\title{
Maximum oxygen uptake and cardiovascular response of Professional male football and Basketball players to Chester step test.
}

\author{
Ibikunle P.O ${ }^{1}$, Enumah U.G ${ }^{1}$. \\ ${ }^{I}$ Department of Medical Rehabilitation, Faculty of Health sciences and Technology, Nnamdi Azikiwe University, \\ Nnewi campus Nnewi, Nigeria. \\ All correspondence to Peter Ibikunle (Phd, Pt)Department of Medical rehabilitation, Nnamdi Azikiwe
}

\begin{abstract}
The cardiovascular response to exercise has several variables but this study will be limited to the heart rate response, blood pressure response and predicted $\mathrm{VO}_{2}$ max. These variables are what this study will be utilizing to evaluate the fitness level of the participants. The purpose of this study was to estimate the maximum oxygen uptake $\left(\mathrm{VO}_{2} \mathrm{max}\right)$ and compare the cardiovascular response of professional male football players and basketball players to Chester step bench test.A total of 100 athletes (50 football players and 50 basketball players) recruited through convenience sampling participated in the study. The research design was quasi experimental research design. The instruments used were heart rate monitor, electronic blood pressure monitor, $30 \mathrm{~cm}$ Chester step, stop watch, mobile metronome version 1.2.4, height meter, bathroom scale. The $\mathrm{VO}_{2}$ max was estimated from $\mathrm{HR}$ recovery (HRrec) after 15seconds using the equation $\mathrm{VO}_{2}$ max $=111.3-(0.42$ $x H R r e c)$.Comparative analysis of the data was done using descriptive statistics of mean and standard deviation, and inferential statistics of independent t-test with alpha level of significance of 0.05. In the result, Significant differences were recorded between the $\mathrm{VO}_{2}$ max of football players $81.15 \mathrm{~kg} / \mathrm{ml} / \mathrm{min}$ and basketball players $72.39 \mathrm{~kg} / \mathrm{ml} / \mathrm{min}$; heart rate $72.10 \mathrm{bpm}$ and $93.58 \mathrm{bpm}$; systolic blood pressure $147.90 \mathrm{mmHg}$ and $142.46 \mathrm{mmHg}$; while there was no statistically significant difference in their diastolic blood pressure $81.820 \mathrm{mmHg}$ and $81.020 \mathrm{mmHg}$. The study showed that football players had significantly higher $\mathrm{VO}_{2} \mathrm{max}(81.14 \pm 0.66 \mathrm{ml} / \mathrm{kg} / \mathrm{min})$, than the basketball players $(72.38 \pm 0.78 \mathrm{ml} / \mathrm{kg} / \mathrm{min})$, indicating that football players had more aerobic capacity than basketball players. High $\mathrm{VO}_{2}$ max is the primary indicator of aerobic fitness, cardiovascular health, and endurance performance. Coaches of different football clubs and basketball clubs should take serious the matter of consistent training of their players to improve and avoid decline in their cardiorespiratory fitness. Individuals should cultivate the habit of exercising in order to improve their cardiorespiratory fitness and minimize the risk of some diseases associated with low cardiorespiratory fitness.
\end{abstract}

Keywords: Maximum oxygen consumption, Chester, bench step, Football, Basketball

\section{Introduction}

Maximum oxygen uptake $\left(\mathrm{VO}_{2}\right.$ max) is defined as the highest rate at which oxygen can be taken up and utilized by the body during severe exercises [1]. It is one of the main variables in the field of exercise physiology and is frequently used to indicate the cardiorespiratory fitness of an individual [1]. Therefore it is a major measure that indicates the functional capacity of the cardiorespiratory system [2]. In the scientific literature, an increase in $\mathrm{VO}_{2} \max$ is the most common method of demonstrating a training effect and so it is frequently used in the development of an exercise prescription [1].

The current concept of $\mathrm{VO}_{2}$ max began with the work of Hill and Lupton where he defined the maximum oxygen uptake and stated that there is a linearly related relationship between workload and oxygen consumption [3]. He went ahead to show that as exercise intensity increases, oxygen consumption increases proportionally. However, that there comes a point at which the oxygen consumption ceases to rise. This point he referred to as the maximal oxygen uptake $\left(\mathrm{VO}_{2} \max \right)$.

It has been shown that $\mathrm{VO}_{2}$ max for different people may be affected by several factors which include; age, gender, fitness and training, changes in altitude and action of the ventilator muscles [4]. The terms $\mathrm{VO}_{2}$ max; aerobic power, aerobic capacity and maximal oxygen uptake are all terms used interchangeably. $\mathrm{VO}_{2}$ max is expressed either as an absolute rate in litres of oxygen per minute $(1 / \mathrm{min})$ or as a relative rate in millilitres of oxygen per kilogram of body weight per minute $(\mathrm{ml} / \mathrm{kg} / \mathrm{min})$.

The cardiovascular response to exercise has several variables but this study will be limited to the heart rate response, blood pressure response and predicted $\mathrm{VO}_{2}$ max. These variables are what this study will be utilizing to evaluate the fitness level of the participants. 
Competitive basketball is an intermittent high intensity physical activity that requires a well- developed aerobic and anaerobic fitness[5]. Although basketball performance is thought to be mainly dependent on players' anaerobic ability, high aerobic fitness is also important for improved performance [6]. Specifically maximal aerobic power $\left(\mathrm{VO}_{2} \mathrm{max}\right)$ is considered to improve the ability to recover from the anaerobic efforts during the game [7]. A professional basketball player is one whose source of livelihood is basketball; he plays the game and earns his living from it.

Football is the most popular sport played all over the world. It is the game that leads in the field of sports [8]. Football involves millions of players, coaches, scientists, administrators, physical education teachers, politicians and inevitably parents of young players. The profound beauty of football in any of its codes lies in the fact that football requires power, accuracy and coordination. Unlimited options are assessed, decisions are taken and action is conducted in less than a second during the course of every game [8]. Football, also known as soccer, is considered a physically demanding sport [9]. The energy demands of football involve all the three systems for production of energy. There are three major systems available for production of energy in muscles: Adenosine Triphosphate- phosphocreatine (ATP- PC) system for high-intensity short bursts; the anaerobic glycolysis system for intermediate bursts of relatively high intensity and finally, there is aerobic system for long efforts of low to moderate intensity [10]. $\mathrm{VO}_{2} \max$ is the primary indicator of aerobic fitness, cardiovascular health, and endurance performance $[11,12,13]$. The direct measurement of $\mathrm{VO}_{2}$ max is the criterion measure, or "gold standard" of aerobic capacity where the participant undergoes a maximal exercise test on a cycle ergometer or treadmill and oxygen consumption is measured directly [11]. Whilst this is the gold standard, the equipment is expensive, impractical in non-laboratory and field-tests situations and also, it requires a high level of technical expertise and supervision. It is unsuitable for individuals also for whom exhaustive exercise is not recommended [11, 14]. As a result, many other tests have been developed for estimation of aerobic capacity [15]. Some of these tests are field tests requiring maximum effort, for example the 20mins multiple shuttles run [15]. However, there are submaximal tests which have been developed for this purpose also, Examples include; submaximal treadmill, cycle ergometer or bench stepping tests with single stage or multistage protocols [16]. The basic premise of submaximal testing is that a linear relationship exists between heart rate and oxygen consumption $[17,18]$

Step tests are one of the most widely used field tests for estimating VO2 max [19]. Stepping requires no elaborate or expensive equipment, no calibration, and can be easily administered to large numbers of people $[20,21]$. Most commonly administered step tests are performed at a fixed cadence on a bench of a fixed height [22]. One such test is the Chester Step Test (CST) which was originally developed by Kevin Sykes at University College Chester to assess the aerobic fitness by predicting maximal aerobic power $\left(\mathrm{VO}_{2} \max \right)$ in fire brigades in Britain, Europe, USA and Asia and more recently for work with airport fire fighters, the ambulance service, health authorities and corporate institutions [23]. The CST is one of many tests designed to provide a safe and practical means of assessing aerobic fitness under submaximal conditions [24]. The limited equipment needed makes the Chester step test very portable and requirement for space is minimal, which is advantageous compared with similar protocols using treadmills, shuttle walks or cycle ergometer [25]. It has been shown that investigators should choose the appropriate bench height for convenience of the participants [25]. The Chester Step has a height ranging from $15 \mathrm{~cm}$ to $30 \mathrm{~cm}[23]$.

Several researchers have suggested that, if a step is too high, local muscular fatigue may ensue before a true assessment of aerobic capacity can be obtained, so the test may be more a measure of muscular endurance of the legs than of aerobic capacity [19].

Studies have shown that a good level of aerobic capacity is important for good performance for athletes [15], also athletes lose their aerobic capacity as a result of neglect in keeping to their training. A sub-optimal level of cardiorespiratory fitness is a risk factor for coronary heart disease and other chronic diseases among adults, such as colorectal cancer, type II diabetes, depression, and is associated with all-cause mortality. It also leads to poor performance and frequent fatigue among athletes during competitions [15, 26, 27, 28]

Research Design:

II. Methodology

A quasi experimental expost facto research design was used.

Sample Size:

The sample size for this study was 100 male participants comprising 50 football and 50 basketball players from a well-known and registered professional sports clubs.

\section{Instrumentation:}

Chester Step Test Data Collection and Results (CST DC\&R) sheet were used to gather the information needed e.g. Name, age, Sex, weight etc.

I Chester step of $30 \mathrm{~cm}$ high was constructed in Nigeria. 
II Mobile Metronome (Android Mobile version 1.2.4)

III A Heart Rate monitor (Pulse Sonic model K901A) made in United Kingdom

IV Bathroom scale (model Hamason, China)

V Stop watch (Kadio model KD-1069, China)

VI Height Meter (made in Nigeria)

VII An electronic blood pressure monitor (made in China)

\section{Procedure for Data Collection:}

Ethical approval was sought and obtained from the Ethical Review Committee of Nnamdi Azikiwe University Teaching Hospital Nnewi. Also, informed consent was sought and obtained. All participants were familiarized with the Chester Step and the Heart rate Monitor. The details of the study were explained to the prospective participants. Upon arrival at the venue of the research, each participant rested for at least 5 minutes after which resting blood pressure and heart rate were taken in a sitting position.

\section{Exercise Protocol:}

Chester Step Test (CST) as developed by Sykes requires the subject to step on to and off a low step at a rate set by a metronome [23]. Upon arrival at the research venue, the participants are to rest for at least 5 minutes after which their resting heart and blood pressure was taken. Then the metronome was set at 96 beats per minute a stepping rate of 24steps per minute. The participant continued this for 3 minutes or get down when they are tired. At the end the blood pressure was measured immediately and the recovery heart rate recorded after 15 seconds.

Aerobic capacity and fitness rating was then estimated using the recovery heart rate after 15 seconds using the equation $\mathrm{VO}_{2} \max =111.33-(0.42 \times$ HRrec $)$ developed by McArdle (2000) for step bench estimation of maximum oxygen uptake where HRrec is the $15 \mathrm{sec}$ recovery heart rate.

\section{Data Analysis:}

The data obtained from this study were analyzed using descriptive statistics of mean and standard deviation, and inferential statistic of independent t-test with the level of significance set at 0.05 .

\section{Results And Discussion}

\section{Anthropometric Measures for Professional Male Football and Basketball Players}

Tables 1 and 2 show the means and standard deviations of the professional players anthropometric variables age, height, and weight.

\section{Estimated Maximum Oxygen Uptake ( $\left.\mathrm{VO}_{2} \mathrm{Max}\right)$}

As shown in Table 3; The $\mathrm{VO}_{2}$ max of football players $(81.15 \pm 4.72 \mathrm{ml} / \mathrm{kg} / \mathrm{min}$.) was significantly higher $(\mathrm{P}<$ $0.001)$ than that of basketball players $(72.39 \pm 5.58 \mathrm{ml} / \mathrm{kg} / \mathrm{min})$

\section{Physiological Responses of Professional Male Football and Basketball players to Chester Step Test.}

The results are shown in Table 3, with the average heart rate of football players after the test as $72.1 \pm 1.62 \mathrm{bpm}$ and the average heart rate of basketball players after the test as $93.58 \pm 1.94 \mathrm{bpm}$. The heart rate shows a good cardiovascular conditioning to exercise.

The diastolic blood pressure with an average of $81.82 \pm 0.86 \mathrm{mmHg}$ for the football players, and $81.02 \pm 0.76 \mathrm{mmHg}$ for the basketball players, and the systolic blood pressure with the average for football players as $147.9 \pm 1.61 \mathrm{mmHg}$ and basketball players as $142.46 \pm 1.61 \mathrm{mmHg}$.

Table 1: Anthropometric Measures of Football players

\begin{tabular}{|cccc|}
\hline Age(Yrs) & \multicolumn{2}{c|}{ Height(M) } & \multicolumn{2}{c|}{ Weight(Kg) } \\
Mean & 21.20 & 1.76 & 71.82 \\
\hline S.D & 4.69 & 0.07 & 7.69 \\
\hline
\end{tabular}

Table 2: Anthropometric measures for basketball players

\begin{tabular}{|llcc|}
\hline & Age(Yrs) & Height $(\mathbf{M})$ & Weight $($ Kg) \\
\hline Mean & 22.26 & 1.81 & 77.58 \\
S.D & 3.57 & 0.07 & 11.52 \\
\hline
\end{tabular}


Table 3: $\mathrm{VO}_{2}$ max, Heart Rate and Blood Pressure parameters of professional male football players and basketball players.

\begin{tabular}{|c|c|c|c|c|c|c|}
\hline & & $\mathrm{N}$ & Mean & Standard Deviation & t-value & P-value \\
\hline $\begin{array}{l}\mathrm{VO}_{2} \\
(\mathrm{Kg} / \mathrm{ml} / \mathrm{min})\end{array}$ & $\begin{array}{l}\text { Football players } \\
\text { Basketball } \\
\text { Players }\end{array}$ & $\begin{array}{l}50 \\
50 \\
\end{array}$ & $\begin{array}{l}81.146 \\
72.388 \\
\end{array}$ & $\begin{array}{l}4.72 \\
5.58\end{array}$ & 8.48 & $0.000 *$ \\
\hline $\begin{array}{ll}\text { Heart } & \text { Rate } \\
\text { (Beats/min) } & \end{array}$ & $\begin{array}{l}\text { Football players } \\
\text { Basketball } \\
\text { Players }\end{array}$ & $\begin{array}{l}50 \\
50 \\
\end{array}$ & $\begin{array}{r}72.100 \\
93.580 \\
\end{array}$ & $\begin{array}{r}11.46 \\
13.73 \\
\end{array}$ & -8.49 & $0.000 *$ \\
\hline $\begin{array}{l}\text { Diastolic Blood } \\
\text { Pressure }(\mathrm{mmHg})\end{array}$ & $\begin{array}{l}\text { Football players } \\
\text { Basketball } \\
\text { Players }\end{array}$ & $\begin{array}{l}50 \\
50 \\
\end{array}$ & $\begin{array}{l}81.820 \\
81.020 \\
\end{array}$ & $\begin{array}{l}6.14 \\
5.44 \\
\end{array}$ & -8.49 & 0.49 \\
\hline $\begin{array}{l}\text { Systolic Blood } \\
\text { Pressure }(\mathrm{mmHg})\end{array}$ & $\begin{array}{l}\text { Football players } \\
\text { Basketball } \\
\text { Players }\end{array}$ & $\begin{array}{l}50 \\
50 \\
\end{array}$ & $\begin{array}{l}147.90 \\
142.46 \\
\end{array}$ & $\begin{array}{l}11.39 \\
11.39 \\
\end{array}$ & 2.39 & $0.02 *$ \\
\hline
\end{tabular}

\section{Discussion}

\section{The $\mathrm{VO}_{2}$ max of professional male football and basketball players.}

The study showed that football players had significantly higher $\mathrm{VO}_{2} \max (81.14 \pm 0.66 \mathrm{ml} / \mathrm{kg} / \mathrm{min})$, than the basketball players $(72.38 \pm 0.78 \mathrm{ml} / \mathrm{kg} / \mathrm{min})$, indicating that football players had more aerobic capacity than basketball players. High $\mathrm{VO}_{2} \max$ is the primary indicator of aerobic fitness, cardiovascular health, and endurance performance $[11,12,13]$. This is in line with the work of David and Howley, where it was stated that an increase in $\mathrm{VO}_{2}$ max is the most common method of demonstrating a training effect on the cardiorespiratory system [1]. The amount of distance covered during the game of football has a role to play in the significantly higher $\mathrm{VO}_{2}$ max of football players is in line with the work of Bangsbo which showed a significant relation between $\mathrm{VO}_{2}$ max and distance covered during the match [29]. This shows that football is a more demanding sport in the area of intensity of workload, total miles covered and duration during training and the game itself, than the basketball. It can be said that the reason behind a higher $\mathrm{VO}_{2}$ max of football players compared to basketball players is the combined effect of covered distance owing to the large football pitch and a longer duration of play when compared to basketball pitch and duration of play.

\section{Heart rate response of professional male football and basketball players to Chester Step Test.}

The study showed a lower mean heart rate of football players $72.1 \pm 1.62 \mathrm{bpm}$ than the basketball players $93.58 \pm 1.94 \mathrm{bpm}$ in response to the submaximal step test. This is in line with the work of Carter, Eric \& Blaber who reported that long-term endurance training also decreases submaximal exercise heart rate by reducing sympathetic activity to the heart [30]. Carter, Eric, \& Blaber also showed that cardiovascular adaptation to exercise involves integration of neural and local factors [30]. Neural factors which include: (i) central command; (ii) baroreceptor reflex action; and (iii) neural reflex feedback from contracting muscle. Smith et al opined that it is possible that chronic endurance exercise can alter autonomic function and depress baroreflex control by decreasing baroreceptor sensitivity; he reported that sensitivity of the arterial baroreflex was significantly reduced in young adults with high cardiorespiratory fitness compared with young adults with moderate cardiorespiratory fitness [31]. Evans et al reported that peripheral adaptation such as duration of the exercise, total area covered during exercise that are associated with training may also contribute to exercise bradycardia[32]. So it can be said that the lower heart rate of football players compared to the basketball players as observed in this study is as a result of the combined effect of both the altered autonomic function, decreased sensitivity of the baroreceptor, and peripheral adaptation.

\section{Blood pressure response of professional male football and basketball players to Chester Step Test.}

The study revealed that football players had significantly higher systolic blood pressure $147.9 \pm 1.61 \mathrm{mmHg}$ than the basketball players $142.46 \pm 1.61 \mathrm{mmHg}$ whereas their diastolic blood pressures are $81.82 \pm 0.86 \mathrm{mmHg}$ and $81.02 \pm 0.76 \mathrm{mmHg}$ were not significantly different. The increase in systolic blood pressure and the insignificant increase in the diastolic blood pressure of both groups observed at the end of the test is a normal physiologic response to exercise. Whelton et al reported that chronic aerobic exercise exerts a significant anti-hypertensive effect and Pescatello and Kulikowich reported that acute exercise results in post-exercise hypotension [33, 34]. The underlying mechanisms relating to anti-hypertensive benefits are not completely understood, however several studies have shown connections to specific physiological mechanisms [35]. An immediate reduction in blood pressure following exercise has been termed 'post-exercise hypotension' and is agreed to be caused by reductions in vascular resistance. The mechanisms associated with the chronic adaptations to blood pressure are more complex. A recent meta-analysis supports this chronic role being partially explained by a decreased systemic vascular resistance in which the autonomic nervous system and renin-angiotensin system (a hormone system that helps normalize long-term blood pressure and blood volume in the body) are most likely the 
underlying regulatory mechanisms [36]. Another factor contributing to this decrease in vascular resistance is the increase of nitric oxide production causing a vasodilation in response to regular aerobic exercise [35].

\section{Conclusion}

Based on the findings of this study the following conclusions were reached:

1. Football players have significantly higher $\mathrm{VO}_{2} \max$ than Basketball players.

2. Football players have significantly lower heart rate than basketball players

3. Football players have significantly higher systolic blood pressure than basketball players

4. Football players and basketball players have statistically insignificant difference in their diastolic blood pressure.

\section{References}

[1]. David, R.B \& Howley E.T (2000). Limiting factors for maximum oxygen uptake and determinants of endurance performance. Journal of Med. Sci. Sports Exercise, 32(1), 70-84.

[2]. Edward H.T, Bassett D.R and Welch H. G.(1995). Criteria for maximum oxygen uptake; review and uptake and commentary. Journal of Medical Science and Sports Exercise; 27(9): 1292-1301.

[3]. Hill A.V \& Lupton H. (1923). Muscular exercise, Lactic acid and the supply of oxygen. Journal of Medicine; 16:35-171.

[4]. Noakes, T.D., Peltonen, J.E \& Rusko H.K Jr. (2001).Evidence that a central governor regulates exercise performance during acute hypoxia and hyperoxia.J.Exp.Biol.204, 3225-3234

[5]. McInnes, S.E., Carlson J.S., Jones C.J \& McKenna M.J (1995) The physiological load imposed on basketball players during competition .J Sport sci, 13(5), 387-97

[6]. Stone, W.J \& Steingard P.M (1993).Year round conditioning for Basketball. Clinics in sport Medicine 12,173-91.

[7]. Tomlin, D.L\& Wenger, H.A (2001).The relationship between aerobic fitness and recovery from high intensity intermittent exercise. Sport Med.31 (1),1-11

[8]. $\quad$ Feza K. (2007). Uniting Science and the art of football. Journal of sport science and Medicine vol 6(10), 1-2.

[9]. Al'Hazzaa H. M, Almuzaini K. S \& Al Rafaee S. A. (2001). Aerobic and anaerobic power characteristic of Saudi elite soccer players. Journal of sports Medicine and physical fitness; 41:54-61

[10]. Mc Ardle, W.D., Katch F.I\& Katch V.L. (1996). Cardiovascular System and Exercise $4^{\text {th }}$ edition Baltimore MD: Williams and Wilkins, 198-211.

[11]. American College of Sports Medicine (ACSM). (2000). Guidelines for exercise testing and prescription $6^{\text {th }}$ edition Lippincott, Williams \& Wikkins 3-10, 57-80.

[12]. Anderson G. S,(1992) Comparison of predictive test of aerobic capacity. Canadian Journal of Sport Science. (1992). 17:304-308.

[13]. 13.Zwiren, L.P\& Freedson, A. (1991). Advanced Fitness assessment and exercise prescription. Human Kinetics 9th edition Lippincott, Williams \& Wilkins ,312-319

[14]. Astrand, P.O., Rodal, S.B., Dahl, H.A\& Stromme A .(2003). Textbook of work physiology. New York, Human Kinetics.

[15]. Leger, L.A., Mercier, D \& Gadourg C. (1988). Journal of Sports Science, 6, 93-101.

[16]. Heyward, V. H. (2002). Advanced Fitness assessment and exercise prescription. Human

[17]. $\quad$ Kinetics $9^{\text {th }}$ edition Lippincott, Williams \& Wilkins ,312-319

[18]. Pollock, M.L \& Wilmore, J.H. (1990). Essentials of Exercise Physiology; Philadelphia; PA: W.B Saunders.

[19]. Mc Ardle, W.D., Katch F.I\& Katch V.L. (2000). Essentials of Exercise Physiology $2^{\text {th }}$ edition Baltimore MD: Williams and Wilkins, 124-140.

[20]. 19.Culpepper, M.I \& Francis, K.T (1987).An anatomical model to determine step height in step testing for estimating aerobic capacity. Journal of Theor Biol, 129, 1-8.

[21]. 20. Margarita, R., Aghemo P\& Rovelli E. (1965). Journal of Applied Physiology, 20(2),1070-1073.

[22]. 21. Selig,S.E., Goshing, C.M \& Carlson, J.S(2000).Clinical kinesiology,54,67-71

[23]. 22. Davis, J \& Wilmore, J (1979) Validation of a bench stepping test for cardiorespiratory fitness classification of emergency service personnel. Journal of Occupational Medicine, 21,671-673.

[24]. 23. Sykes K. (1998). Chester Step Test; resource pack (version 3) Cheshire, UK: Chester College of Higher Education,

[25]. 24. Buckley, J.P., Eston, R.G\& Sim, J. (2000) Rating of perceived exertion in Braille: Validity and Reliability in production mode. Brazilian Journal of Sports Medicine; 34:297-302.

[26]. 25. McArdleW.D, Katch F.I, Katch V.L, (2000).Essentials of Exercise Physiology; $2^{\text {nd }}$ edition; Philadelphia, Lippincott Williams and Wilkins.126-140.

[27]. 26.Blair, S.N., Kohl, H.W., Paffenburger, R.S Jr.,Clark, D.G., Cooper, K.H\& Gibbon, L.W (1989) Physical fitness and all-cause mortality. A Prospective study of Healthy men and women.JAMA,3, 262(17),2395-401

[28]. 27. Berlin, J.A., Colditz, G.A. (1990). A meta-analysis of physical activity in prevention of coronary Heart disease. American Journal of Epidemiology vol 132,(4);612-628

[29]. 28.Helmrich, S.P., Ragland, D.R., Leung, A.B \& Paffenburger, R.S Jr(1991) Physical activity and reduced occurrence of non-insulin dependent diabetes mellitus. $N$ Engl J med 325:147-152

[30]. 29. Bangsbo, J. (1994). Energy demands in competitive soccer. Journal of Sports Science 1994; 12 (3):S5-12.

[31]. 30. Carter, J.B., Eric, W.B \& Andrew, B.P. (2003). Effect of endurance exercise on autonomic control of heart rate. Journal of Sport Medicine; 33(1),33-46

[32]. 31. Smith, M.L., Hudson, D \& Graitzer H (1989). Exercise training bradycardia: the role of autonomic balance. Journal of Medical Science and Sports Exercise 1989; 21 (1), 40-4

[33]. 32. Evans, J.M., Ziegler, M \& Patwardhan, A.R (2001). Gender differences in autonomic cardiovascular regulation: spectral, hormonal, and hemodynamic indexes. Journal of Applied Physiology 2001; 91 (2), 54-60.

[34]. 33. Whelton, S.P., Chin, A., Xin, X\& He, J. (2002). Effect of aerobic exercise on blood pressure: a meta-analysis of randomised controlled trials. Annals of Internal Medicine 136, 493-503.

[35]. 34. Pescatello, L.S \& Kulikowich, J.M (2001). The after effects of dynamic exercise on ambulatory blood pressure. Medicine and Science in Sport and Exercise 33, 1855-1861.

[36]. 35. Hillman G.C \& Kravitz L (2007) Hypertension and Exercise.www.unm.edu retrieved January 2014.

[37]. 36. Cornelissen, V.A\& Fagard, R.H (2005).Effect of resistance training on resting blood pressure: a meta-analysis of randomized controlled trials. J.Hypertension .23(2), 251-9 